\title{
A NEED ANALYSIS OF ENGLISH LEARNING FOR DESIGNING ENGLISH CURRICULUM AND WORKSHEET \\ (A Case Study for the sixth semester of Electrical Engineering Students in the Academic Year of 2015/2016 at State Polytechnic of Cilacap)
}

\author{
Betti Widianingsih ${ }^{1}$ dan Rostika Listyaningrum ${ }^{2}$ \\ ${ }^{1}$ Electrical Engineering Department, State Polytechnic of Cilacap \\ ${ }^{2}$ Informatic Engineering Department, State Polytechnic of Cilacap \\ Email : $\underline{\text { betti_widianingsih@yahoo.com }}$
}

\begin{abstract}
The purpose of english learning in higher education level is used as mean to develop the competence of language skill which includes listening, speaking, reading, and writing. English is one of basic course which being compulsory course followed by students. The way of english learning for engineering students differs from english learning for english department students. ESP is an english learning with specific purposes. It aims to make students able to master english skill based on their discipline. It is designed to prepare english learners in specific job and discipline for reaching specific goals. Therefore, this research aims to find out and describe student's need for english learning, and also explain the importance of english in a workplace in the field of engineering. The research involved the sixth semester of Electrical Engineering students in the academic year 2015/2016, lectures in Electrical engineering department at State Polytechnic of Cilacap and stakeholders. The method of collecting data used questionnaire and direct interview. The finding of the research is becoming a reference to create the syllabus design or development of worksheet for ESP. From the research, it can be clearly concluded that english learning should be focused on the language skill and also adjusted to the student's need for electrical engineering and preparation to work.
\end{abstract}

Key words : need analysis, ESP, english learning, electrical engineering student

\section{Abstrak}

Di tingkat perguruan tinggi, tujuan pembelajaran bahasa Inggris digunakan sebagai sarana mengembangkan kompetensi keterampilan berbahasa mahasiswa yang mencakup mendengarkan, berbicara, membaca, dan menulis. Bahasa Inggris merupakan Mata Kuliah Dasar Umum yang menjadi mata kuliah wajib yang diajarkan. Sebagai Mata Kuliah Dasar Umum pada non program studi bahasa Inggris, arah pembelajaran bahasa Inggris untuk non program studi bahasa Inggris berbeda dengan bahasa Inggris pada program studi bahasa Inggris. English for Specific Purposes (ESP) adalah bahasa Inggris untuk tujuan khusus. ESP bertujuan agar pembelajar mampu menguasai bahasa Inggris pada bidang yang mereka pelajari dan biasa dikenal sebagai mata kuliah Bahasa Inggris bagi mahasiswa non program studi bahasa Inggris. ESP didesain untuk menyiapkan pembelajar bahasa Inggris yang digunakan dalam disiplin ilmu dan pekerjaan tertentu demi mencapai tujuan tertentu. Oleh karena itu, penelitian ini bertujuan untuk menemukan dan mendeskripsikan kebutuhan terhadap pembelajaran ESP pada mahasiswa dan pentingnya peranan bahasa Inggris pada dunia kerja dalam bidang keteknikan. Penelitian ini melibatkan mahasiswa semester enam tahun ajaran 2015/2016, Dosen Program studi Teknik Elektronika Politeknik Negeri Cilacap, dan juga stakeholders. Teknik pengumpulan data yang digunakan adalah kuesioner dan melakukan wawancara langsung. Hasil penelitian ini akan digunakan sebagai acuan untuk membuat silabus maupun pengembangan materi atau bahan ajar untuk bahasa Inggris ESP. Dari hasil penelitian dapat ditarik kesimpulan bahwa pengajaran bahasa lebih difokuskan pada keterampilan bahasa, topik bahan ajar dipilih sesuai dengan disiplin ilmu dan kebutuhan di dunia kerja.

Kata Kunci : analisis kebutuhan , ESP, pembelajaran bahasa inggris, mahasisa teknik elektronika 


\section{PENDAHULUAN}

\begin{tabular}{lcr}
\multicolumn{1}{c}{ Pada era globalisasi } & saat ini, \\
kebutuhan & kemampuan & berbahasa \\
inggris sangat dibutuhkan & seiring \\
dengan & meningkatnya & tingkat \\
mobilisasi & manusia. & Tingginya \\
mobilisasi & memicu & komunikas \\
internasional antar bangsa semakin
\end{tabular} mudah sehingga menjadikan bahasa inggris sebagai bahasa internasional dan berperan sebagai lingua franca. Untuk mempelajari bahasa inggris tentunya disesuaikan dengan kebutuhan dan tujuan pembelajar sendiri. Ada empat kemahiran berbahasa yang belum tentu semuanya dibutuhkan oleh pembelajar yaitu menulis (writing), membaca (reading), berbicara (speaking) dan mendengar (listening). Namun kebutuhan ketrampilan berbahasa Inggris tersebut tidaklah sama, karena semua orang memiliki kebutuhan masingmasing disesuaikan dengan bidang yang digelutinya. Hal ini menuntut dunia pendidikan khususnya tingkat perguruan tinggi untuk terlebih dahulu mengenal pembelajarnya serta kebutuhannya akan kemampuan berbahasa Inggris. Dengan melaksanakan analisis kebutuhan sebelum menyusun sebuah program pembelajaran, pembelajar dan penyusun kurikulum dapat mengetahui dengan jelas program pembelajaran seperti apa yang dibutuhkan calon pembelajarnya.

Analisa kebutuhan merupakan cara untuk mengetahui perbedaan atau gap antara apa yang sudah diketahui mahasiswa dengan apa yang mereka ingin tahu. Hyland dalam Paltridge and Starfield (2013) menjabarkan definisi analisis kebutuhan (needs analysis) sebagai berikut :

"Needs analysis refers to the techniques for collecting and assessing information relevant to course design: it is the means of establishing the how and what of a course. It is a continuous process, since we modify our teaching as we come to learn more about our students, and in this way it actually shades into evaluation the means of establishing the effectiveness of a course. Needs is actually an umbrella term that embraces many aspects, incorporating learners' goals and backgrounds, their language proficiencies, their reasons for taking the course, their teaching and learning preferences, and the situations they will need to communicate in. Needs can involve what learners know, don't know or want to know, and can be collected and analyzed in a variety of ways."

Ada dua jenis kebutuhan, yaitu Target Needs dan Learning Needs. Target needs merupakan apa yang perlu dilakukan oleh siswa atau pembelajar pada situasi tertentu. Dengan kata lain elemen-elemen linguistik apa yang dibutuhkan untuk mencapai tujuan komunikasi tertentu. Hutchinson and Waters (1987) memaparkan komponen yang termasuk dalam target needs, yaitu necessities, lacks dan wants. Sementara itu, learning needs adalah apa yang perlu dilakukan pembelajar atau siswa untuk tujuan belajar. Robinson (1991: 7) mengemukakan "learning needs are "...what the learner needs to do to actually acquire the language”. Dalam pengajaran bahasa, analisis kebutuhan berkaitan erat dengan pengajaran bahasa dengan tujuan tertentu atau English For Spesific Purposes (ESP) yang merupakan pendekatan untuk mendesain kurikulum yang dimulai dengan pertanyaan mengapa peserta didik perlu belajar bahasa inggris. Anthony dalam Lamri "Some people described ESP as simply being the teaching of English for any purpose that could be specified. Others, however, were more precise describing it as the teaching of English used in 
academic studies or the teaching of English for vocational or professional purposes".

Di Politeknik Negeri Cilacap, mata kuliah bahasa Inggris diajarkan dengan jumlah beban 2 sks teori dan 2 sks praktek, dan ditempuh pada semester gasal atau genap tergantung kurikulum pada tiap-tiap program studi. Sebagai Mata Kuliah Dasar Umum pada non program studi bahasa Inggris, arah pembelajaran bahasa Inggris untuk non program studi bahasa Inggris seharusnya berbeda dengan bahasa Inggris pada program studi bahasa Inggris. Oleh karena itu, topik dan istilah yang digunakan pada disiplin ilmu tiap program studi berbeda, sehingga itu pembelajaran bahasa Inggris bagi mahasiswa non program studi bahasa Inggris perlu dianalisis dan nantinya akan ditemukan bahasa Inggris seperti apa yang sesuai dengan minat dan kebutuhan mahasiswa. Sementara itu, penerapan materi untuk bahan ajarnya pun masih bersifat umum (General English) dan belum sesuai dengan bidang ilmu yang sedang dipelajari.

Beberapa penelitian yang berkaitan dengan analisis kebutuhan (need analysis) sudah banyak dilakukan, seperti Sukarni (2016), Indrasari (2016), Irmawati (2016), Purwanto (2014), Izidi (2017) dan Atefi Boroujeni (2013) yang mendeskripsikan analisis kebutuhan bahasa inggris mahasiswa pada program studi non bahasa inggris. Penelitian tersebut menjadi acuan peneliti untuk mengkaji lebih lanjut pada kondisi mahasiswa di Politeknik Negeri Cilacap yang memang belum menerapkan pembelajaran bahasa inggris berbasis ESP. Karenanya, penulis perlu melakukan analisis kebutuhan (need analysis). Tujuan dari penelitian ini adalah unntuk menemukan dan mendeskripsikan kebutuhan terhadap pembelajaran ESP pada mahasiswa dan pentingnya peranan bahasa Inggris pada dunia kerja.

\section{METODE PENELITIAN}

Penelitian ini melibatkan beberapa kategori responden, seperti mahasiswa semester 6 (enam) tahun ajaran 2015/2016 berjumlah 72, 11 dosen teknik elektronika dan 6 stakeholders dari industri sebagai objek penelitian. Metode penelitian yang digunakan studi kasus deskriptif yaitu mendeskripsikan masalah dan kebutuhan siswa dalam mempelajari bahasa Inggris dengan tujuan khusus (ESP). Sumber data berupa sumber data primer dan sekunder. Data primer diambil dari hasil kuesioner berupa angket maupun wawancara. Data sekunder berupa dokumen berupa jurnal dan buku referensi yang berkaitan dengan penelitian ini. Pengumpulan data dilakukan dengan menyebarkan kuesioner ke mahasiswa dan dosen program studi Teknik Elektronika. Selanjutnya melakukan wawancara (interview) dengan pihak stakeholders atau perusahaan industri.

Berikut adalah kerangka penelitian analisis kebutuhan mahasiswa program studi teknik Elektronika semester 6 Tahun Ajaran 2015/2016 di Politeknik Negeri Cilacap.

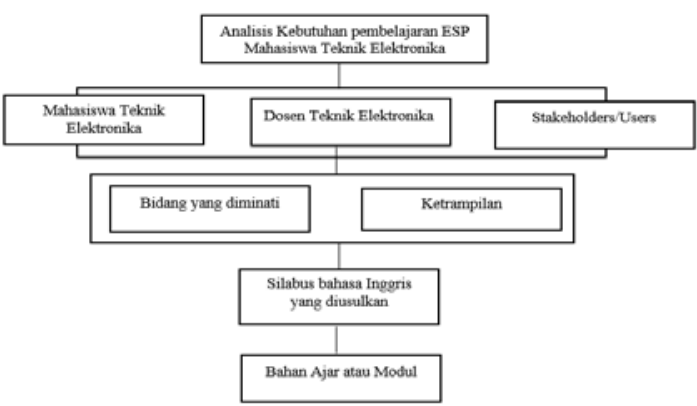

Gambar 1. Kerangka Penelitian : diadopsi dari Richard (2001 : 52) 


\section{HASIL DAN PEMBAHASAN}

Pada hasil dan pembahasan di penelitian ini, penulis membagi penjabaran hasil kuesioner dan wawancara berdasarkan pada 3 aspek, yaitu (1) Necessities (kebutuhan), (2) Lacks (kelemahan ), dan (3) Wants (keinginan) untuk mencapai goal (tujuan pembelajaran bahasa Inggris). (Hutchinson \& Waters, 1987)

\section{Necessities (Kebutuhan) \\ Kebutuhan mahasiswa terhadap pembelajaran bahasa inggris berbasis ESP}

Tabel 1. Tabel Pertanyaan 1

\begin{tabular}{llll}
\hline \multicolumn{1}{c}{ Pertanyaan } & \multicolumn{3}{c}{ Pilihan (Persentase) } \\
\cline { 2 - 3 } & $\begin{array}{l}\text { Penting } \\
\text { Sekali }\end{array}$ & $\begin{array}{l}\text { Benting } \\
\text { Saja }\end{array}$ \\
\hline $\begin{array}{l}\text { Menurut anda seberapa } \\
\text { pentingkah bahasa inggris } \\
\text { itu? }\end{array}$ & 63,8 & 34,7 & 1,3 \\
\hline
\end{tabular}

Tabel 2. Tabel pertanyaan 2

\begin{tabular}{llrc}
\hline \multicolumn{2}{c}{ Pertanyaan } & \multicolumn{2}{c}{ Pilihan (Persentase) } \\
\cline { 3 - 4 } & & Ya & Tidak \\
\hline $\begin{array}{l}\text { Menurut Anda, apakah } \\
\text { bahasa inggris }\end{array} \begin{array}{r}\text { akan } \\
\text { berperan penting dalam }\end{array}$ & 98,6 & 1,4 \\
$\begin{array}{l}\text { pekerjaan Anda yang } \\
\text { akan datang? }\end{array}$ & & \\
\hline
\end{tabular}

Dari tabel pertanyaan 1 dapat diketahui bahwa mahasiswa yang menyatakan bahasa inggris penting sekali sebesar $63,8 \%$, penting berjumlah $34,7 \%$ dan biasa saja berjumlah $1,3 \%$. Hal ini menunjukkan bahwa bahasa inggris menjadi salah satu mata kuliah penting yang dapat membantu mahasiswa mempersiapkan diri menghadapi dunia kerja seperti hasil kuesioner pada tabel pertanyaan 2 yang menjelaskan 98,6\% mahasiswa menyatakan bahasa inggris penting untuk membekali mereka masuk ke dunia kerja, sedangkan hanya 1,4\% mahasiswa menyatakan tidak penting.

Tabel 3. Tabel pertanyaan 3

\begin{tabular}{|c|c|c|c|}
\hline \multirow[t]{2}{*}{ Pertanyaan } & \multicolumn{3}{|c|}{ Jawaban } \\
\hline & Responden 1 & Responden 2 & Responden 3 \\
\hline $\begin{array}{l}\text { Jika Ya, dalam hal } \\
\text { apakah bahasa inggris } \\
\text { dapat berperan penting } \\
\text { dalam pekerjaan Anda } \\
\text { yang akan datang? }\end{array}$ & $\begin{array}{l}\text { Dalam hal } \\
\text { perancangan } \\
\text { kebutuhan pekerjaan } \\
\text { biasanya terdapat } \\
\text { kata" bahasa inggris } \\
\text { dalam bentuk file } \\
\text { maupun laporan dan } \\
\text { berbicara kepada } \\
\text { orang asing yang } \\
\text { menjalin kerja sama } \\
\text { di perusahaan }\end{array}$ & $\begin{array}{l}\text { Interview dan } \\
\text { presentasi }\end{array}$ & $\begin{array}{l}\text { Spesifikasi } \\
\text { komponen } \\
\text { aplikasi software } \\
\text { mikrokontroler } \\
\text { maupun plc dan } \\
\text { lain lain }\end{array}$ \\
\hline
\end{tabular}

Tabel 4. Tabel pertanyaan 4

\begin{tabular}{lccccc}
\hline \multicolumn{2}{c}{ Pertanyaan } & \multicolumn{4}{c}{ Pilihan (Prosentase) } \\
\cline { 2 - 5 } & Mendengarkan & Membaca & Berbicara & Menulis \\
\hline $\begin{array}{l}\text { Menurut Anda, ketrampilan } \\
\text { berbahasa inggris apa yang perlu } \\
\text { anda kuasai? }\end{array}$ & 19,4 & 2,7 & 73,6 & 4,1 \\
\hline
\end{tabular}


Data di atas mewakili 72 responden yang terlibat dalam penelitian ini. Responden 1 menyatakan bahwa bahasa inggris penting dikuasai untuk kebutuhan pekerjaan. Mahasiswa akan seringkali dihadapkan pada istilahistilah khusus berbahasa inggris dalam bidang keteknikan di lingkungan pekerjaannya, sehingga pemahaman dan penguasaan kosakata bahasa inggris mutlak diperlukan. Hal ini juga disampaikan oleh responden 3, bahasa inggris perlu dikuasai agar mampu menjelaskan komponen-komponen mikrokontoler maupun PLC. Sementara itu, responden lain menyatakan bahasa inggris penting untuk keperluan wawancara (interview) dan presentasi. Dari 3 pendapat responden tersebut, dapat diambil kesimpulan bahwa kemampuan berkomunikasi dengan bahasa inggris perlu dikuasai mahasiswa, seperti yang disajikan pada tabel pertanyaan 4. Ketrampilan berbahasa yang perlu dikuasai mahasiswa adalah berbicara, yaitu sebesar 73,6\%. Sementara itu, ketrampilan mendengarkan sebanyak $19,4 \%$, menulis $4,1 \%$ dan membaca $2,7 \%$. Begitu pula data yang relevan diperoleh dari hasil wawancara dari stakeholders pada tabel wawancara 1 berikut ini.

\section{KebutuhanDosen Program Studi Teknik Elektronika terhadap pembelajaran bahasa inggris berbasis ESP}

Tabel 5. Tabel pertanyaan 1

\begin{tabular}{|c|c|c|c|c|}
\hline \multirow{2}{*}{ Pertanyaan } & \multicolumn{4}{|c|}{ Pilihan (Persentase) } \\
\hline & Berbicara & Menulis & Membaca & Mendengarkan \\
\hline $\begin{array}{l}\text { Dari beberapa ketrampilan } \\
\text { berbahasa } \\
\text { kemampuan (skill) apa yang } \\
\text { menurut Anda paling } \\
\text { dibutuhkan mahasiswa } \\
\text { Teknik Elektronika }\end{array}$ & 90,9 & 9,1 & (2) & -8 \\
\hline
\end{tabular}

Tabel 6. Tabel pertanyaan 2

\begin{tabular}{lcccc}
\hline \multicolumn{1}{c}{ Pertanyaan } & \multicolumn{3}{c}{ Pilihan (Persentase) } \\
\cline { 2 - 5 } & Penting sekali & Penting & $\begin{array}{c}\text { Tidak } \\
\text { penting }\end{array}$ & $\begin{array}{c}\text { Biasa } \\
\text { saja }\end{array}$ \\
\hline $\begin{array}{l}\text { Apakah penting bagi mahasiswa } \\
\text { Teknik Elektronika mempelajari } \\
\text { cara presentasi dalam bahasa }\end{array}$ & 54,5 & 45,5 & 0 & 0 \\
$\begin{array}{l}\text { inggris } \\
\begin{array}{l}\text { Apakah penting bagi mahasiswa } \\
\text { Teknik Elektronika mempelajari }\end{array}\end{array}$ & 45,5 & & & \\
$\begin{array}{l}\text { cara melakukan wawancara kerja } \\
\text { dengan bahasa inggris }\end{array}$ & & 54,5 & 0 & 0 \\
\hline
\end{tabular}

Dari 4 (empat) jenis ketrampilan berbahasa, 90,9\% dosen menyatakan kemampuan berbicara adalah ketrampilan yang paling dibutuhkan, sedangkan 9,1 $\%$ menyatakan ketrampilan menulis. Hal ini membuktikan bahwa kemampuan berkomunikasi sangat dibutuhkan oleh mahasiswa agar mereka siap bersaing dengan mahasiswa lulusan program studi lain untuk masuk ke dunia industri. Mahasiswa mampu berkomunikasi langsung dengan bahasa inggris dengan client atau customer. Karenanya, kemampuan berbicara 
menjadi ketrampilan yang paling signifikan dibutuhkan mahasiswa. Ketrampilan berkomunikasi yang dibutuhkan mahasiswa meliputi presentasi, diskusi dan bahkan melakukan wawancara kerja sesuai dengan hasil kuesioner pada tabel pertanyaan 2. Dosen yang menyatakan presentasi dengan bahasa inggris penting sekali sebesar $54,5 \%$, sedangkan dosen menyatakan penting sebesar 45,5\%. Sementara itu, 45,5\% dosen menyatakan penting sekali bagi mahasiswa belajar cara melakukan wawancara dan $54,5 \%$ penting. Dari perolehan prosentase tersebut, dapat disimpulkan bahwa kemampuan presentasi dan wawancara dengan bahasa inggris perlu dikuasai oleh mahasiswa.

\section{Kebutuhan Stakeholders/Users terhadap pembelajaran bahasa inggris berbasis ESP}

Tabel 7. Tabel Hasil wawancara 1

\begin{tabular}{|c|c|c|}
\hline \multirow[t]{2}{*}{ Pertanyaan } & \multicolumn{2}{|c|}{ Jawaban } \\
\hline & Responden 1 & Responden 2 \\
\hline $\begin{array}{l}\text { Apakah } \\
\text { bahasa inggris } \\
\text { penting } \\
\text { digunakan } \\
\text { dalam dunia } \\
\text { industri? }\end{array}$ & $\begin{array}{lr}\text { "Penting, akan } \\
\text { tetapi } \\
\text { menyesuaikan } \\
\text { dengan bidang } \\
\text { pekerjaan yang } \\
\text { bersangkutan. } \\
\text { Karena tidak } \\
\text { semua } \\
\text { disemua } \\
\text { departemen } \\
\text { punya wajib } \\
\text { bahasa inggris } \\
\text { yang bagus" }\end{array}$ & 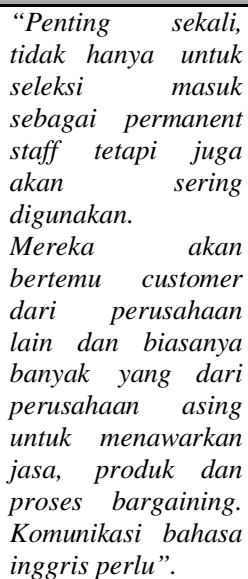 \\
\hline
\end{tabular}

\section{Lack (Kekurangan)}

$\begin{array}{lcr}\text { Lack (Kekurangan) } & \text { kemampuan } \\ \text { bahasa } & \text { inggris } & \text { mahasiswa } \\ \text { berdasarkan } & \text { hasil } & \text { kuesioner } \\ \text { mahasiswa } & & \end{array}$

Tabel 8 Tabel pertanyaan 1

\begin{tabular}{llll}
\hline \multicolumn{1}{c}{ Pertanyaan } & \multicolumn{3}{c}{ Pilihan (Persentase) } \\
\cline { 2 - 4 } & Bagus & Biasa & Kurang \\
\hline $\begin{array}{l}\text { Bagaimana Anda } \\
\text { menilai kemampuan } \\
\text { berbahasa inggris }\end{array}$ & 16,7 & 50 & 33,3 \\
\hline
\end{tabular}

Tabel 9 Tabel pertanyaan 2

\begin{tabular}{|c|c|c|c|}
\hline \multirow[b]{2}{*}{ Pertanyaan } & \multicolumn{3}{|c|}{ Jawaban } \\
\hline & $\begin{array}{l}\text { Respon } \\
\text { den } 1\end{array}$ & $\begin{array}{l}\text { Respon } \\
\text { den } 2\end{array}$ & $\begin{array}{l}\text { Respon } \\
\text { den } 3\end{array}$ \\
\hline $\begin{array}{lr}\text { Selama Anda belajar } \\
\text { di program studi ini, } \\
\text { kesulitan apa sajakah } \\
\text { yang Anda temui } \\
\text { berkaitan } & \text { dengan } \\
\text { bahasa inggris? } & \end{array}$ & $\begin{array}{l}\text { grammar } \\
\text { dan kosa } \\
\text { kata. }\end{array}$ & $\begin{array}{l}\text { penguca } \\
\text { n yang } \\
\text { kurang } \\
\text { fasih, } \\
\text { kurang } \\
\text { memaha } \\
\text { grammal }\end{array}$ & $\begin{array}{l}\text { aPresentasi } \\
\text { bahasa } \\
\text { inggris }\end{array}$ \\
\hline
\end{tabular}

Dari hasil di atas, dapat disimpulkan bahwa prosentase jumlah mahasiswa yang menilai kemampuan bahasa inggrisnya biasa yaitu 50\%, kurang $33,3 \%$ dan bagus 16,7\%. Kurangnya kemampuan bahasa inggri mereka dikarenakan kesulitan mengikuti pembelajaran bahasa inggris seperti yang tercantum pada tabel pertanyaan 2 . Responden 1 menyatakan tata bahasa (grammar) merupakan salah satu materi yang sulit untuk dipelajari, sedangkan responden 2 menyampaikan pengucapan (prononciation) yang belum fasih menjadi kendala utama dalam mempelajari bahasa inggris. Sementara itu, responden 3 mengalami kesulitan saat diminta melakukan presentasi bahasa inggris.

Tabel 10. Tabel pertanyaan 3

\begin{tabular}{lllll}
\hline \multirow{2}{*}{ Pertanyaan } & \multicolumn{4}{c}{ Pilihan (Persentase) } \\
\cline { 2 - 5 } & $\begin{array}{l}\text { Sulit } \\
\text { sekali }\end{array}$ & Sulit & Mudah & $\begin{array}{l}\text { Mudah } \\
\text { sekali }\end{array}$ \\
\hline $\begin{array}{l}\text { Seberapa sulitkah } \\
\text { Anda melakukan } \\
\text { presentasi dalam } \\
\text { bahasa inggris? }\end{array}$ & 12,5 & 52,7 & 31,9 & 2,7 \\
$\begin{array}{l}\text { Seberapa sulitkah } \\
\text { Anda memahami } \\
\text { grammar bahasa } \\
\text { inggris? }\end{array}$ & 9,7 & 62,5 & 26,3 & 1,3 \\
\end{tabular}

Berdasarkan data di atas, peneliti dapat menyimpulkan bahwa jumlah mahasiswa yang menyatakan tata bahasa (grammar) sulit sejumlah 62,5\% mahasiswa, mudah 26,3 \%, sulit sekali 9,7\% dan mudah sekali 1,3\%. Sementara 
itu, ketrampilan berkomunikasi yang dianggap sulit adalah presentasi, yaitu sejumlah $52,7 \%$, sedangkan $31,9 \%$ mahasiswa mengatakan mudah, 12,5\% sulit sekali dan 2,7\% mahasiswa mengatakan mudah sekali. Dalam hal ini, pembelajaran tentang tata bahasa (grammar) berkaitan dengan presentasi. Beberapa mahasiswa masih menganggap jika mereka mempunyai tata bahasa (grammar) yang bagus berarti kemampuan berbicara (speaking) juga bagus.

\section{Lack (Kekurangan) kemampuan bahasa inggris mahasiswa berdasarkan hasil kuesioner dosen}

Tabel 11.Tabel pertanyaan 1

\begin{tabular}{|c|c|c|c|c|c|}
\hline \multirow[b]{2}{*}{ Pertanyaan } & \multicolumn{5}{|c|}{ Pilihan (Persentase) } \\
\hline & $\begin{array}{l}\text { Berbica } \\
\text { ra }\end{array}$ & $\begin{array}{l}\text { Tata } \\
\text { bahasa }\end{array}$ & $\begin{array}{l}\text { Penguas } \\
\text { aan } \\
\text { kosakat } \\
\text { a }\end{array}$ & Menulis & $\begin{array}{l}\text { Memba } \\
\text { ca }\end{array}$ \\
\hline $\begin{array}{l}\text { Kemampuan } \\
\text { (skill) apa }\end{array}$ & & & & & \\
\hline $\begin{array}{l}\text { yang menurut } \\
\text { Anda perlu } \\
\text { dikembangka } \\
\mathrm{n} \text { untuk } \\
\text { mahasiswa } \\
\text { Teknik } \\
\text { Elektronika }\end{array}$ & 0 & 3 & 8 & 0 & 0 \\
\hline
\end{tabular}

Dari hasil tabel pertanyaan di atas, dapat disimpulkan bahwa kemampuan atau ketrampilan berbahasa yang perlu dikembangkan adalah penguasaan kosa kata. 8\% dosen teknik elektronika menyatakan kemampuan mahasiswa dalam penguasaan kosa kata masih kurang, sehingga perlu ada media pembelajaran yang menarik sehingga dapat meningkatkan penguasaan kosa kata. Sementara itu, dosen yang menyatakan kemampuan tata bahasa mahasiswa yang harus dikembangkan sebesar 3\%.
Lack (Kekurangan) lulusan berdasarkan hasil wawancara stakeholders / users

Tabel 12.Tabel Hasil wawancara 1

\begin{tabular}{|c|c|c|}
\hline \multirow[t]{2}{*}{ Pertanyaan } & \multicolumn{2}{|c|}{ Jawaban } \\
\hline & Responden 1 & Responden 2 \\
\hline $\begin{array}{l}\text { Sebagai salah } \\
\text { satu perusahaan } \\
\text { pengguna } \\
\text { lulusan, dari } 4 \\
\text { ketrampilan } \\
\text { berbahasa } \\
\text { inggris mana } \\
\text { yang masih } \\
\text { perlu } \\
\text { dikembangkan? }\end{array}$ & $\begin{array}{l}\text { “Menulis, tiap } \\
\text { bagian ada } \\
\text { tugas untuk } \\
\text { membuat email } \\
\text { dengan bahasa } \\
\text { inggris. } \\
\text { Pemahaman } \\
\text { mereka menulis } \\
\text { email dan } \\
\text { laporan dengan } \\
\text { bahasa inggris } \\
\text { kurang”. }\end{array}$ & $\begin{array}{l}\text { "Kemampuan } \\
\text { berbicara untuk } \\
\text { memasarkan } \\
\text { produk } \\
\text { perusahaan" }\end{array}$ \\
\hline
\end{tabular}

Data di atas menunjukkan kemampuan berkomunikasi dan menulis menjadi ketrampilan yang wajib dikuasai. Dari aspek kekurangan (Lack) yang diperoleh 3 kategori responden menyatakan kemampuan berbicara masih kurang.

Wants (Keinginan)

Wants (Keinginan) pembelajaran

bahasa inggris yang diinginkan mahasiswa berdasarkan hasil kuesioner

Tabel 12. Tabel pertanyaan 1

\begin{tabular}{lcccc}
\hline \multicolumn{1}{c}{ Pertanyaan } & \multicolumn{5}{c}{ Pilihan (Persentase) } \\
\cline { 2 - 5 } & $\begin{array}{l}\text { Menden } \\
\text { garkan }\end{array}$ & $\begin{array}{l}\text { Memb } \\
\text { aca }\end{array}$ & $\begin{array}{l}\text { Berbic } \\
\text { ara }\end{array}$ & $\begin{array}{l}\text { Menuli } \\
\text { s }\end{array}$ \\
\hline $\begin{array}{l}\text { Ketrampilan } \\
\text { berbahasa apa yang } \\
\text { paling anda suka? }\end{array}$ & 11,1 & 33,3 & 41,6 & 13,8 \\
\hline
\end{tabular}

Tabel 13. Tabel pertanyaan 2

\begin{tabular}{lrrcc}
\hline \multirow{2}{*}{ Pertanyaan } & \multicolumn{3}{c}{ Pilihan (Persentase) } \\
\cline { 3 - 5 } & & Diskusi & Ceramah & $\begin{array}{l}\text { Praktek langsung } \\
\text { di lapangan }\end{array}$ \\
\hline $\begin{array}{l}\text { Menurut } \\
\text { bagaimana } \\
\text { belajarbahasa } \\
\text { yang menarik? }\end{array}$ & $\begin{array}{r}\text { Anda, } \\
\text { teknis } \\
\text { inggris }\end{array}$ & 15,2 & 2,7 & 81,9 \\
& & & \\
\hline
\end{tabular}

Data di atas menunjukkan bahwa ketrampilan yang paling banyak diminati oleh mahasiswa adalah berbicara (speaking) sebesar 41,6\%. Selanjutnya $33.3 \%$ dari seluruh responden menyukai pembelajaran bahasa inggris membaca (reading), sedangkan menulis (writing) sebesar 13,8\% dan mendengarkan (listening)11,1\%. Ketrampilan berbicara 
mempunyai prosentase paling besar diantara ketrampilan berbahasa lainnya. Sementara itu, sebanyak 81,9\% mahasiswa menyatakan suka belajar bahasa inggris dengan cara praktek langsung di lapangan, sedangkan 15,2\% menyukai diskusi dan 2,7\% ceramah.

Tabel 14. Tabel pertanyaan 3

\begin{tabular}{|c|c|c|c|c|}
\hline \multirow[b]{2}{*}{ Pertanyaan } & \multicolumn{4}{|c|}{ Pilihan (Persentase) } \\
\hline & $\begin{array}{c}\text { Lebih } \\
\text { percaya } \\
\text { diri } \\
\text { mengguna } \\
\text { kan } \\
\text { bahasa } \\
\text { inggris }\end{array}$ & $\begin{array}{l}\text { Menunja } \\
\text { ng studi }\end{array}$ & $\begin{array}{c}\text { Prestig } \\
\text { e } \\
\text { (Keban } \\
\text { ggan) }\end{array}$ & $\begin{array}{l}\text { Kepentin } \\
\text { gan } \\
\text { pekerjaan }\end{array}$ \\
\hline $\begin{array}{l}\text { Menurut Anda, } \\
\text { apakah keuntungan } \\
\text { yang akan Anda } \\
\text { diperoleh setelah } \\
\text { menyelesaikan } \\
\text { pembelajaran } \\
\text { bahasa inggris? }\end{array}$ & 62,5 & 12,5 & 0 & 25 \\
\hline
\end{tabular}

Dari tabel di atas, diperoleh 62,5\% mahasiswa lebih percaya diri apabila mereka mempunyai kemampuan bahasa inggris yang mahir, 25\% untuk kepentingan pekerjaan, sedangkan $12,5 \%$ untuk menunjang studi. Tidak ada satupun mahasiswa yang menyatakan untuk kebanggaan (prestige).

Tabel 15.Tabel pertanyaan 4

\begin{tabular}{llllc}
\hline \multirow{2}{*}{ Pertanyaan } & \multicolumn{4}{c}{ Pilihan (Persentase) } \\
\cline { 2 - 5 } & $\begin{array}{l}\text { Kegiatan } \\
\text { sehari- } \\
\text { hari }\end{array}$ & $\begin{array}{l}\text { Sesuai } \\
\text { dengan } \\
\text { disiplin } \\
\text { ilmu }\end{array}$ & IPTEKS & $\begin{array}{l}\text { Yang } \\
\text { berhubung } \\
\text { an dengan } \\
\text { pekerjaan }\end{array}$ \\
\hline $\begin{array}{l}\text { Topik atau } \\
\text { materi pem- } \\
\text { belajaran } \\
\text { bahasa inggris }\end{array}$ & & 11,1 & 22,2 & 40,2 \\
\hline
\end{tabular}

Topik yang paling banyak diminati oleh mahasiswa adalah yang berhubungan dengan pekerjaan sebesar 40,2\%. 26,3\% dari seluruh responden menyampaikan kegiatan sehari-hari dan 22,2\% IPTEKS.
Wants (Keinginan) pembelajaran bahasa inggris yang diinginkan dosen Teknik Elektronika berdasarkan hasil kuesioner

\begin{tabular}{|c|c|c|c|c|}
\hline \multirow[b]{2}{*}{ Pertanyaan } & \multicolumn{4}{|c|}{ Pilihan (Persentase) } \\
\hline & $\begin{array}{l}\text { Kegiata } \\
\text { n } \\
\text { sehari- } \\
\text { hari } \\
\text { (Daily } \\
\text { conversa } \\
\text { tional } \\
\text { English) }\end{array}$ & 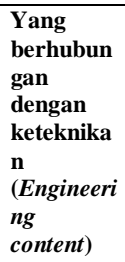 & IPTEKS & $\begin{array}{l}\text { Yang } \\
\text { berhubu } \\
\text { ngan } \\
\text { dengan } \\
\text { pekerja } \\
\text { an }\end{array}$ \\
\hline $\begin{array}{l}\text { Topik atau } \\
\text { materi yang } \\
\text { sesuai untuk } \\
\text { mahasiswa } \\
\text { Teknik }\end{array}$ & 0 & 45,5 & 27,3 & 27,3 \\
\hline
\end{tabular}

Berdasarkan tabel di atas, dapat disimpulkan bahwa 45,5\% menyatakan bahwa Engineering content adalah topik yang sesuai untuk mahasiswa Teknik Elektronika, sedangkan IPTEKS dan topik yang berhubungan dengan pekerjaan mempunyai prosentase yang sama, yaitu 27,3\%. Sementara itu, tidak ada satupun responden yang memilih topik kegiatan sehari-hari (daily conversational english).

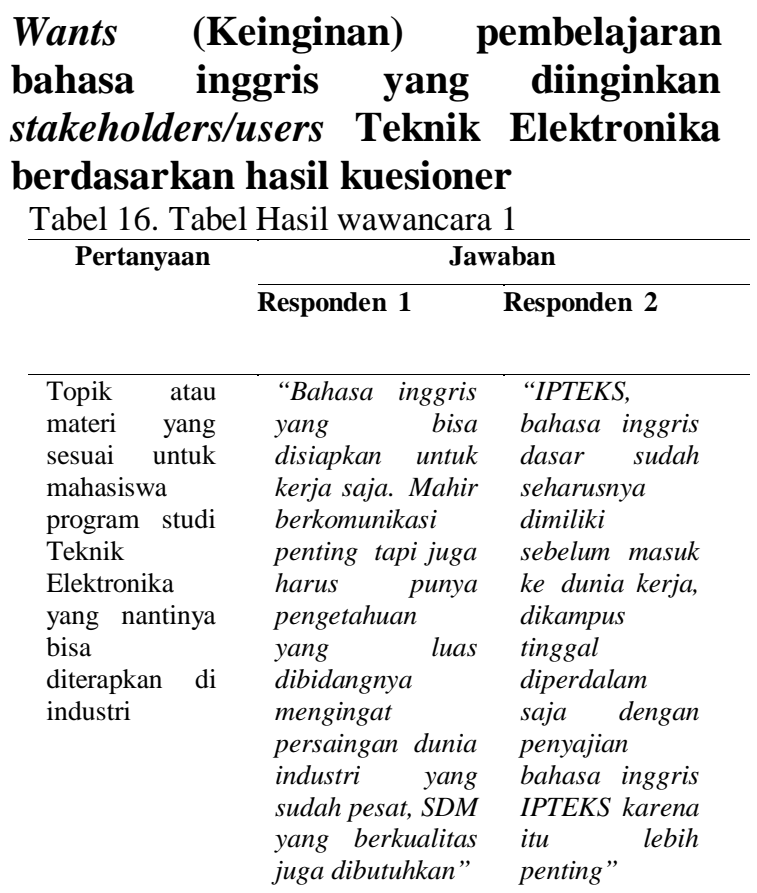

Berdasarkan atau hasil wawancara di atas, dapat disimpulkan bahwa beberapa stakeholders atau users dari industri lebih cenderung memilih topik yang 
berhubungan dengan IPTEKS karena kemampuan berkomunikasi bahasa inggris yang baik harus diimbangi dengan pengetahuan yang baik pula.

\section{KESIMPULAN DAN SARAN}

Berdasarkan hasil penelitian diperoleh bahwa (1) ketrampilan yang paling dibutuhkan adalah berbicara (speaking), karena mereka mengalami kesulitan untuk menyusun kalimat berdasarkan tata bahasa (grammar) inggris yang benar; (2) topik pembelajaran yang diinginkan adalah topik yang berhubungan dengan pekerjaan dan disesuaikan dengan kebutuhan industri (stakeholders/users).

Hasil penelitian ini adalah untuk menyusun silabus dan bahan ajar. Karenanya, peneliti menyarankan dosen bahasa inggris untuk menyusun silabus berbasis ESP untuk pengembangan ketrampilan berbahasa inggris yang bisa diterapkan sesuai dengan tuntutan industri.

\section{DAFTAR PUSTAKA}

Atefi Boroujeni., Samira., \& Moradian Fard, Fateme. (2013). A Need analysis of English for Specific Purposes (ESP) Course For Adoption of Communicative Language Teaching : (A case of Iranian First-Year Students of Educational Administration). International Journal of Humanities and Social Science Invention, 2, 35-44.

Lamri, Chams Eddine. 2016. An Introduction to English for Spesific Purposes (ESP)

Hutchinson, Tom. and Alan. Waters. (1987). English for Specific Purposes: A LearningCentered Approach. Cambridge: University Press

Indrasari., Nunun. (2016). English for Specific Purposes : A need analysis at The Second Semester of Physics Education Students of IAIN Raden Intan Lampung in the Academic Year of 2015/2016. English Education : Jurnal Tadris Bahasa Inggris, 9,161-172

Irmawati. Basri. Rosniati. \& Ashar. (2016). Need Analysis of English For Nurse for Bulukamba Nursing Academy Students. Metalingua, 14, 57-70

Izidi, Redouane., \& Zitouni, Mimouna. (2017). Esp Needs Analysis : the Case of Mechanical Engineering Students at the University of Sciences and Technology. Reveu academique des etudes humaines et sociales. Litterature et Philosophie.No 18. P. 16-25

P.C. Robinson, (1989). An overview of English for specific purposes, in Working with Language: A ultidisciplinary Consideration of Language Use in Work Contexts, H. Coleman, Ed. Berlin: Mouton de Gruyter, 1989, pp. 395-428.

Purwanto., Sugeng. (2014). Needs Analysis of English For Spesific Purposes (ESP) for the Students of Business and Economics Faculty (FEB) UNISBANK Semarang. Dinamika Bahasa dan Ilmu Budaya, 9, 49-59.

Richard., J.C. (2001). Curriculum Development I Language Teaching. Cambridge: Cambrige University Press.

$\begin{array}{ccr}\text { Sukarni, Sri. } & \text { (2016). } & \text { Analisis } \\ \text { Kebutuhan } & \text { Bahasa } & \text { Inggris } \\ \text { Mahasiswa } & \text { Universitas } & \text { Nusa } \\ \text { Tenggara } & \text { Barat. Media } & \text { Bina } \\ \text { Ilmiah ISSN No. 1978-3787. } & \end{array}$


